\title{
Pergeseran Fungsi dan Makna Simbolis Kain Sasirangan
}

\author{
Yunita Fitra Andriana, S.Ds., M.Ds.* \\ Dosen Universitas Trilogi \\ Program Studi Desain Produk, FIKT, Universitas Trilogi, Jakarta
}

\begin{abstract}
Sasirangan cloth is a result of the cultural work of the Banjar people in South Kalimantan, it has its own beauty, characteristics and uniqueness, both in terms of manufacturing techniques, colors, motifs and symbolical meanings. The symbolical meaning that contained in Sasirangan is closely related to its traditional motifs and the natural dyes which it has been used for many years. However, along with the current development, Sasirangan now has changed from using natural dyes to using synthetic dyes, and its traditional motifs that represent symbolical meanings has modified to new forms, so that the symbolical meaning needs to be reexamined. This study of shifting symbolical meanings of Sasirangan cloth uses qualitative methods with literature studies and analysis. The results of this study can be a reference source for studies related to Sasirangan cloth in particular, and traditional Indonesian fabrics in general.
\end{abstract}

Keywords: Dyes, Sasirangan, Symbolical

\section{PENDAHULUAN}

Indonesia merupakan negeri yang memiliki beragam kebudayaan, lengkap dengan berbagai artefak yang lahir dari masing-masing kebudayaan tersebut. Salah satu jenis artefak budaya Indonesia yang diwariskan secara turun temurun adalah kain adat, diantaranya adalah kain Batik, kain Songket, kain Ulos, kain Tapis, kain Besurek, kain Gringsing, kain Lurik dan kain yang akan dikaji lebih jauh dalam kajian ini yaitu, kain Sasirangan.
Kain Sasirangan merupakan kain adat suku Banjar di Kalimantan Selatan yang diwariskan secara turun temurun sejak abad XII, saat Lambung Mangkurat menjadi Patih Negara Dipa. Cerita yang berkembang di masyarakat Kalimantan Selatan adalah bahwa kain Sasirangan pertama kali dibuat oleh Patih Lambung Mangkurat setelah bertapa selama 40 hari 40 malam di atas rakit Balarut Banyu (www.indonesiakaya.com).

Menurut Kholis (2016:1) kain Sasirangan pada awalnya dikenal 
sebagai kain Pamintan, yang dalam bahasa Banjar artinya adalah permintaan, kain ini digunakan ketika seseorang sedang berobat akibat terkena penyakit pingitan. Menurut Ganie dalam Kholis (2016: 2) penyakit pingitan sendiri adalah penyakit yang berasal dari ulah arwah leluhur nenek moyang para bangsawan yang konon tinggal di pantheon atau alam roh.

Seiring perkembangan zaman, kain Pamintan kini lebih dikenal dengan nama kain Sasirangan. Menurut Wijaya (2015: 2), Sasirangan secara harfiah bukanlah merupakan kata benda, "Sa" artinya satu dan "Sirang" artinya jelujur (dijahit). Hal ini sesuai dengan proses pembuatannya yaitu dijelujur (dijahit) kemudian dicelup ke dalam zat pewarna. Pada Zaman dahulu, zat pewarna yang digunakan untuk kain Sasirangan merupakan zat pewarna yang dibuat dari bahanbahan yang bersifat alami, yakni dibuat dari biji, buah, daun, kulit, atau umbi tanaman yang tumbuh liar di hutan atau sengaja ditanam di sekitar tempat tinggal para pembuat kain Sasirangan itu sendiri (www.asik belajar. com). Zat pewarna alami inilah yang dipercaya dapat menyembuhkan berbagai penyakit, selain juga kepercayaan masyarakat Banjar akan motif yang ditampilkan juga dapat menyembuhkan. Seiring dengan perkembangan zaman, kain Sasirangan kini menggunakan zat pewarna sintetis yang menghasilkan ragam warna yang lebih cerah dan lebih awet. Hal ini mempertanyakan kembali makna simbolis dari ragam warna kain Sasirangan yang diyakini mampu mengobati berbagai penyakit.

\section{METODE PENELITIAN}

Metode yang digunakan pada penelitian ini adalah metode kualitatif. Tahap pertama yang dilakukan adalah studi literatur lalu dilanjutkan dengan tahap ke dua yaitu analisa. Pada tahap ke dua ini analisa dilakukan untuk mengidentifikasi pergeseran makna simbolis Sasirangan yang terjadi, baik dari perubahan bentuk motif tradisional dan juga dari perubahan penggunaan pewarna alami menjadi pewarna sintetis. Analisa yang dilakukan merupakan pendapat dari sudut pandang penulis. Oleh karena itu, hasil penelitian ini merupakan kesimpulan dari analisa penulis mengenai objek kajian yang diangkat.

\section{STUDI LITERATUR}

\section{Sejarah Kain Sasirangan}

Awal mula kain Sasirangan terdapat dalam Sahibul Hikayat atau cerita rakyat. Menurut Ganie dalam Kholis (2016:2-3), kain Sasirangan pertama kali dibuat pada sekitar abad XII sampai XIV pada masa kerajaan Dipa di Kalimantan Selatan. Pada saat itu, Patih Lambung Mangkurat bertapa selama 40 hari 40 malam di atas lanting balarut banyu atau di atas rakit mengikuti arus sungai. Menjelang akhir pertapaannya, Patih Lambung Mangkurat tiba di daerah Rantau kota Bagantung. Ia melihat ada seonggok buih dan dari dalam buih tersebut terdengar suara seorang wanita, 
wanita itu adalah Putri Junjung Buih. Patih Lambung Mangkurat berniat untuk menjadikan Putri Junjung Buih tersebut menjadi putri di Kerajaan Negara Dipa, namun Putri Junjung Buih akan muncul ke permukaan jika sejumlah syarat yang dimintanya dipenuhi. Syarat yang ia minta adalah dibuatkan sebuah istana batung atau mahligai megah yang harus selesai dikerjakan dalam tempo satu hari oleh 40 orang pria yang masih bujangan. Selain itu, ia juga minta dibuatkan sehelai kain Langgundi (sekarang dikenal sebagai kain Sasirangan) berwarna kuning yang harus selesai dalam waktu satu hari, yang ditenun dan diwarnai oleh 40 orang wanita yang masih perawan dengan motif padiwaringin. Menurut cerita masyarakat setempat, motif padiwaringin disebut sebagai motif pertama pada kain Sasirangan. Pada hari yang telah disepakati tersebut, naiklah Putri Junjung Buih ke alam manusia meninggalkan tempat persemayamannya selama ini yang terletak di dasar Sungai Tabalong. Ketika itulah warga negara Kerajaan Negara Dipa melihat Putri Junjung Buih tampil dengan anggunnya. Pakaian kebesaran yang dikenakannya pada saat itu tidak lain adalah kain Langgundi berwarna kuning hasil tenunan 40 wanita yang masih perawan.

\section{Fungsi dan Makna Simbolis Kain Sasirangan}

Seiring bergulirnya waktu, kain Langgundi tersebut dipercaya sebagai kain yang mampu menyembuhkan berbagai penyakit. Menurut Wijaya
(2015:1) pada mulanya Kain Sasirangan dikenal dengan nama Kain Pamintan, Pamintan adalah singkatan dari parmintaan (permintaan). Seseorang yang mengidap penyakit berobat kepada seorang yang diyakini sebagai 'orang pintar.' Lalu setelah 'orang pintar' tersebut menerawang penyakitnya, maka ia akan mengajukan permintaan berupa sebuah kain kepada pengrajin kain Pamintan untuk mengobati penyakitnya. Kain Pamintan yang diyakini dapat menyembuhkan ini berwarna dasar kuning dengan pinggiran hijau dan motif modang (ketupat merah) terletak tepat di bagian tengah kain. Dalam kepercayaan agama Hindu, warna kuning dipakai oleh Dewa Wisnu, Krisna dan Ganesha; menjadi simbol kekeramatan dan penangkal dari roh jahat.

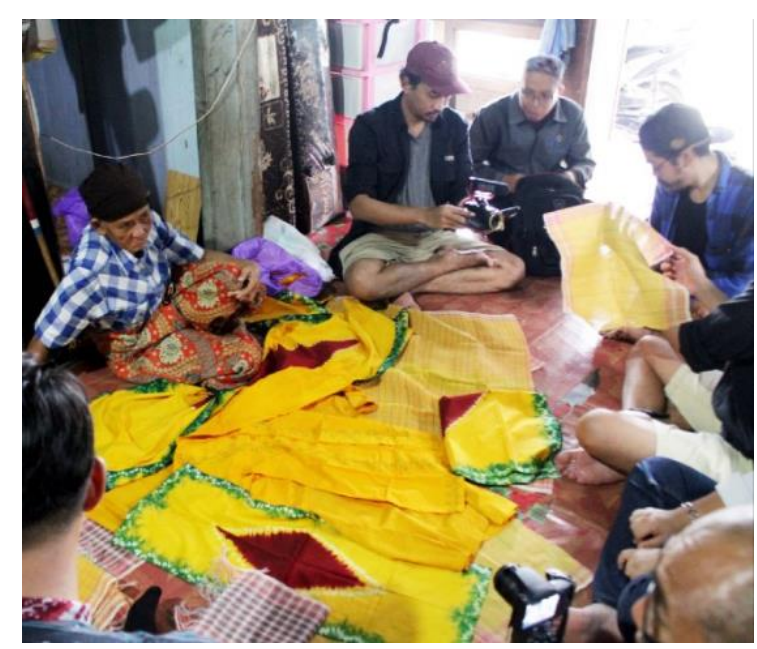

Gambar 1. Pengrajin Kain Pamintan (Sumber: https://medium .com)

Sebelum digunakan, kain Pamintan tersebut diasap dengan dupa dan dibacakan shalawat pada malam Senin dan Jumat. Kemudian dikenakan oleh orang yang sakit sebagai sarung, ikat 
pinggang atau ikat kepala. Kain Pamintan adalah medium doa karena menurut pengrajinnya yang menyembuhkan tetaplah Tuhan (https://medium.com). Berdasarkan penyakitnya, cara penggunaannya kain Pamintan adalah sebagai berikut: 1. Sarung (tapih bahalai) dikenakan sebagai selimut untuk mengobati penyakit demam atau gatal-gatal

2. Bebat (babat atau stagen) yang dililitkan di perut dimaksudkan sebagai sarana untuk menyembuhkan penyakit diare, disentri, kolera, dan sejenis penyakit perut lainnya.

3. Selendang (kakamban) yang dililitkan di kepala atau disampirkan sebagai penutup kepala dimaksudkan sebagai sarana untuk menyembuhkan sakit kepala sebelah (migraine).

4. Ikat kepala (laung) yang dililitkan di kepala dimaksudkan sebagai sarana untuk menyembuhkan penyakit kepala seperti pusing atau kepala berdenyut-denyut (Sumber: https://warisanbudaya.kemdikbud.go .id)

Menurut Wijaya (2015:2) serangkaian proses pengobatan tersebut, terawangan 'orang pintar,' proses pembuatan kain Pamintan serta pemakaiannya sebagai terapi, dilaksanakan agak tertutup artinya tidak terbuka secara umum. Sedangkan menurut Wijaya (2015:2), pada zaman dahulu tidak semua orang bisa menjadi pengrajin kain Pamintan. Hal ini karena keterampilan membuat kain Pamintan merupakan keterampilan yang bersifat keturunan, sehingga keterampilan tersebut tidak mudah diturunkan kepada sembarang orang. Selain itu, terdapat tuntutan tradisi yang mengharuskan diadakannya upacara selamatan sebelum memulai membuat kain Pamintan tersebut. Upacara selamatan tersebut adalah dengan mengadakan sesajian berupa kue khas Banjar, segelas kopi manis, dan kopi pahit, dan disertai dengan perapian yang ditaburi dupa yang berbau harum. Setelah dibacakan do'a selamat, sesajian kue itu dapat dimakan bersama. Ketika upacara selamatan tersebut selesai, barulah dimulai merancang pengolahan kain Pamintan.

Dalam beberapa kasus, ragam hias yang diimbuhkan pada kain Pamintan adalah metafora dari keluhan penyakit si pasien. Seperti contohnya motif kangkung berombak untuk sakit kepala yang seperti terombang ambing, atau motif naga balimbur (naga meliuk) untuk sakit yang melilit-lilit. Motif juga dapat berdasarkan bentuk dari "roh" yang mengganggu orang tersebut; apakah berbentuk buaya, lipan, naga atau ular.

Selain dari segi motif, makna kain Sasirangan yang erat kaitannya dengan khasiat pengobatan juga terletak pada ragam warnanya. Berikut ini merupakan makna simbolis ragam warna kain Sasirangan :

1. Kain Sasirangan warna kuning merupakan tanda simbolik bahwa pemakainya sedang dalam proses mengobati penyakit kuning (bahasa Banjar kana wisa), 
2. Kain Sasirangan warna merah merupakan tanda simbolik bahwa pemakainya sedang dalam proses mengobati penyakit sakit kepala, dan sulit tidur (imsonia),

3. Kain Sasirangan warna hijau merupakan tanda simbolik bahwa pemakainya sedang dalam proses mengobati penyakit lumpuh (stroke),

4. Kain Sasirangan warna hitam merupakan tanda simbolik bahwa pemakainya sedang dalam proses mengobati penyakit demam dan kulit gatal-gatal,

5. Kain Sasirangan warna ungu merupakan tanda simbolik bahwa pemakainya sedang dalam proses mengobati penyakit sakit perut (diare, disentri, dan kolera),

6. Kain Sasirangan warna coklat merupakan tanda simbolik bahwa pemakainya sedang dalam proses mengobati penyakit tekanan jiwa (stress). (https://asikbelajar.com)

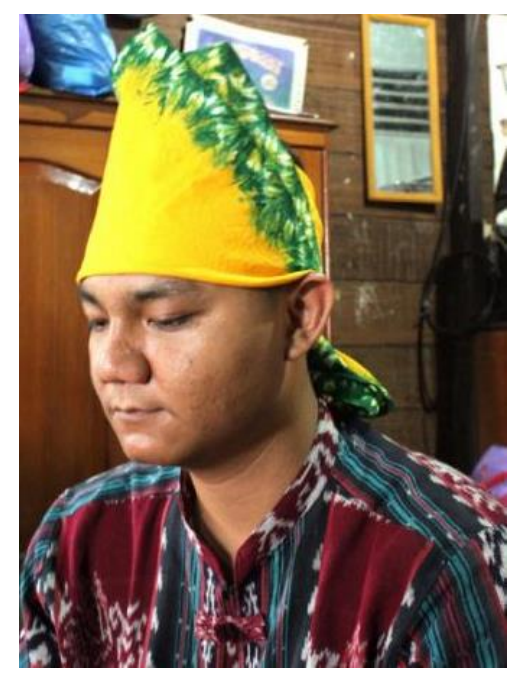

Gambar 2. Kain Pamintan Sebagai Ikat Kepala (Sumber: https://medium .com)

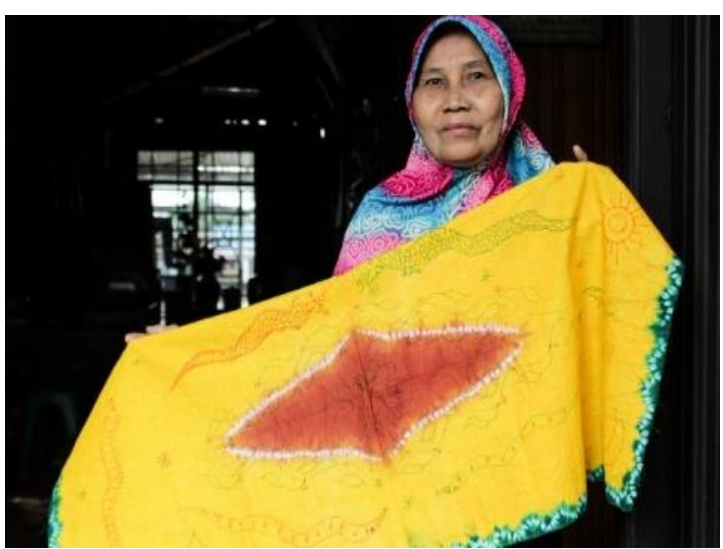

Gambar 3. Pengrajin dan Kain Pamintannya (Sumber: https://medium .com)

\section{Motif Kain Sasirangan}

Terdapat lebih dari 15 motif tradisional kain Sasirangan yang telah diakui oleh pemerintah melalui Dirjen HAKI Departemen Hukum dan HAM RI sebagai berikut : a. Iris Pudak; b. Kambang Raja; c. Bayam Raja; d. Kulit Kurikit; e. Ombak Sinapur Karang; f. Bintang Bahambur; g. Sari Gading; h. Kulit Kayu; i. Naga Balimbur; j. Jajumputan; k. Turun Dayang; 1. Kambang Tampuk Manggis; m. Daun Jaruju; n. Kangkung Kaombakan; o. Sisik Tanggiling; p. Kambang Tanjung (Rosyadi: 2017 h.54)

Saat ini, sejumlah pengrajin kain Sasirangan mendesain motif sendiri yang lebih terkesan modern, misalnya motif berbentuk hewan, berbentuk rumah Banjar dan bahkan terdapat pengrajin yang mau menerima pesanan motif tertentu dari pelanggannya. Hal ini menunjukan bahwa kain Sasirangan kini bisa diproduksi dan dikenakan oleh seluruh lapisan masyarakat tanpa 
perlu merasa khawatir melanggar pakem adat istiadat suku Banjar.

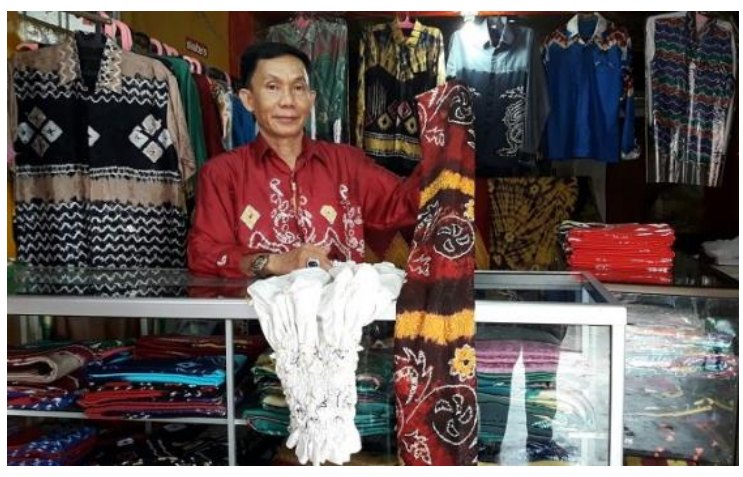

Gambar 19. "Ami" Sasirangan, salah satu pengrajin yang memproduksi kain Sasirangan dengan motif modern (Sumber: http://banjarmasin.tribunnews.com)

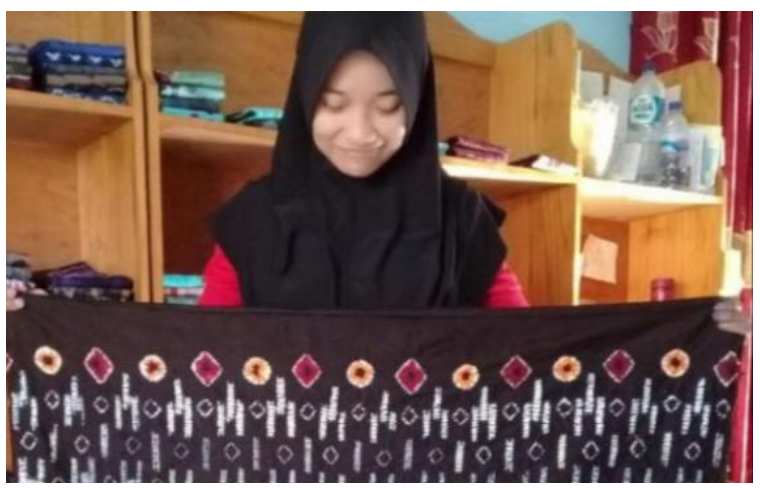

Gambar 20. "Zahra" Sasirangan, pengrajin yang memodifikasi motif klasik Sasirangan menjadi motif baru yang modern (Sumber: http://banjarmasin.tribunnews.com)

\section{HASIL DAN ANALISIS}

\section{Pergeseran Fungsi Kain Sasirangan}

Pada zaman sekarang ini, semakin jarang orang yang menggunakan kain Pamintan sebagai kain yang dipercaya mampu mengobati berbagai penyakit. Hal ini dikarenakan perkembangan zaman yang semakin maju memunculkan sarana dan prasarana sektor pendidikan dan kesehatan yang semakin baik Wijaya (2015:2). Selain itu, juga menurut Wijaya masuknya agama Islam sangat berpengaruh terhadap tradisi Batatamba (berobat) masyarakat Banjar dengan cara menggunakan kain Pamintan ini.

Saat ini, popularitas kain Pamintan sebagai kain khas Banjar memunculkan permintaan pasar yang tidak sedikit. Kini kain Pamintan tersebut lebih dikenal dengan nama kain Sasirangan dan menjadi komoditi industri lokal khas Kalimantan Selatan. Hal ini mengakibatkan kain Sasirangan mengalami perubahan fungsi, menurut Kholis (2016:4), yang pada mulanya kain Sasirangan digunakan sebagai media pengusir roh-roh jahat, sekarang berubah menjadi berbagai macam produk, seperti baju pesta, sandal, tas, dan dompet. Hal ini dapat dilihat dari semakin banyaknya industri kain Sasirangan yang berkembang pesat di Kalimantan Selatan khususnya di daerah Kampung Melayu, kelurahan penghasil kain Sasirangan terbesar yang ada di Kota Banjarmasin, Kalimantan Selatan.

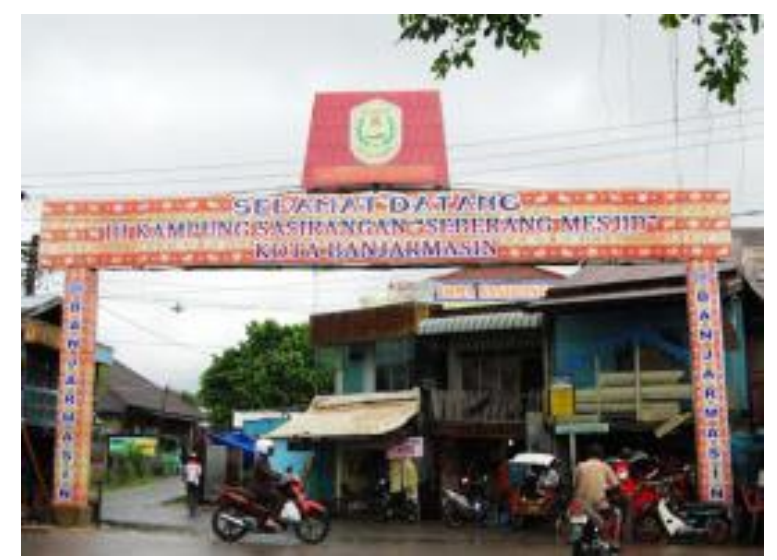


Gambar 21. Kampung Melayu, kelurahan penghasil Sasirangan di Kalimantan Selatan (Sumber: https://bolabolaubikeju.wordpress .com)

Walaupun telah terjadi pergeseran pada fungsi kain Sasirangan, namun hingga saat ini masih ada sekelompok orang tertentu yang masih memegang keyakinan akan kekuatan magis kain Sasirangan. Biasanya, sekelompok orang yang memegang keyakinan ini adalah masyarakat yang masih memiliki darah keturunan Kerajaan Banjar lama, mereka terkadang masih sering mencari kain tradisional Sasirangan untuk sarana penyembuhan suatu penyakit. Keyakinan mereka ini dipengaruhi oleh faktor psikologis hingga mereka mempercayai kain Sasirangan ini memiliki daya magis yang tinggi dan hanya dengan kain Sasirangan inilah penyakitnya akan sembuh (Sumber: https://warisanbudaya.kemdikbud.go .id)

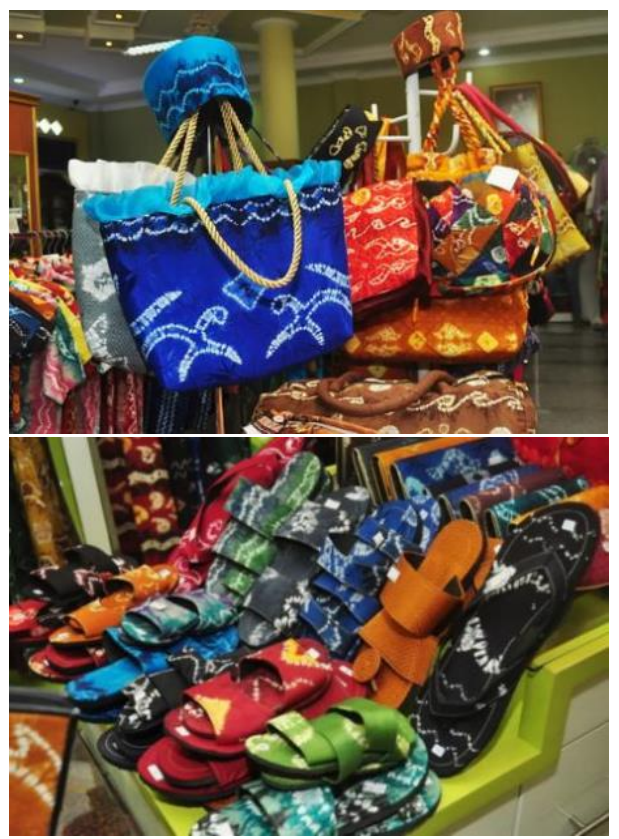

Gambar 22. Ragam Produk dari Kain Sasirangan (Sumber: https://www.smart bisnis.co.id)
Dari segi bahan baku yang digunakan, kain Sasirangan pun mengalami perubahan. Pada awalnya bahan yang digunakan merupakan bahan alami yang terbuat dari serat kapas atau katun. Seiring dengan perkembangan zaman, kini bahan baku yang digunakan bukan saja dari katun, tetapi ada juga kain Sasirangan yang terbuat dari satin dan sutera.

\section{Pergeseran Makna Simbolis Kain Sasirangan}

Pergeseran fungsi kain Sasirangan mengakibatkan pergeseran pada makna simbolisnya. Pada awalnya zat pewarna yang digunakan merupakan zat pewarna alami, yang dengan ini juga keyakinan masyarakat akan kemampuan kain Sasirangan sebagai obat berbagai penyakit semakin kuat. Saat ini, seiring dengan meningkatnya permintaan pasar akan kain Sasirangan, dan juga meningkatnya persaingan antar pengrajin kain tersebut maka banyak pengrajin yang beralih menggunakan zat pewarna sintetis.

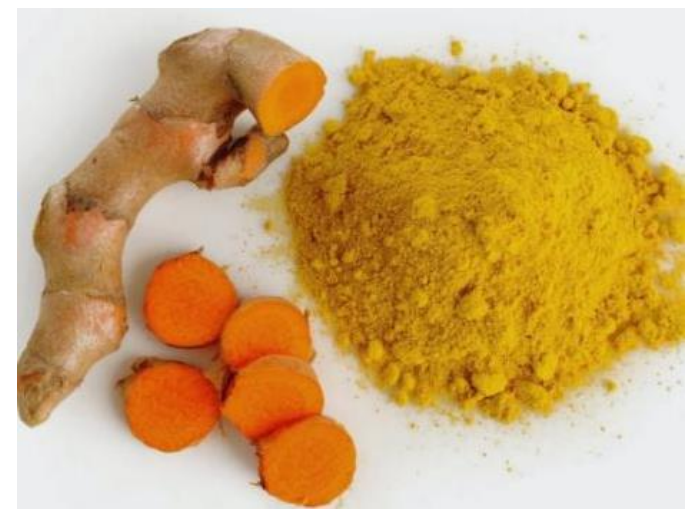

Gambar 23. Kunyit, merupakan salah satu zat pewarna alami yang kerap digunakan untuk Kain Sasirangan (Sumber: http://blogmaya tkj2 di namis.com/) 
Menurut Seman dalam Kholis (2016:

12) jenis pewarna kimiawi atau sintetis yang digunakan oleh pengrajin kain Sasirangan adalah pewarna impor, diantaranya adalah pewarna direct, pewarna basis, pewarna asam, pewarna blerang, pewarna hydron, pewarna bejana, pewarna bejana laut, pewarna naptol, pewarna disperse, pewarna reaktif, pewarna rapid, pewarna pigmen, dan pewarna oksidasi. Selain itu, untuk menambah kesan anggun dan mewah juga digunakan zat pewarna prada. Adapun zat pewarna sintetis dalam bentuk kemasan kaleng mempunyai isi berupa bubuk dalam berbagai warna seperti merah, merah muda, hijau, hijau muda, kuning, coklat, ungu biru tua, hitam, dan masih banyak warna lainnya.

Beralihnya para pengrajin dari zat pewarna alami ke pewarna sintetis dikarenakan bahan-bahan pewarna alami sulit diperoleh dan proses pewarnaannya memakan waktu yang cenderung lama hingga berhari-hari. Sedangkan bahan baku zat pewarna kimia mudah diperoleh, proses pewarnaannya pun cenderung lebih mudah dan cepat. Selain alasan teknis, pangsa pasar kain Sasirangan pun cenderung lebih menyukai warna yang mencolok, yang tidak mungkin diperoleh dari zat pewarna alami.

Kini, pewarna alami untuk kain Sasirangan hanya dipergunakan sebagai bahan pewarna kain Pamintan, meskipun dewasa ini juga sudah jarang dipergunakan. Kain Sasirangan yang sampai saat ini masih menggunakan zat pewarna alami masih dapat ditemukan di Kabupaten Hulu Sungai Tengah dan hanya diproduksi secara terbatas oleh para pengrajin di kabupaten tersebut (http://banjarmasin.tribunnews.com)

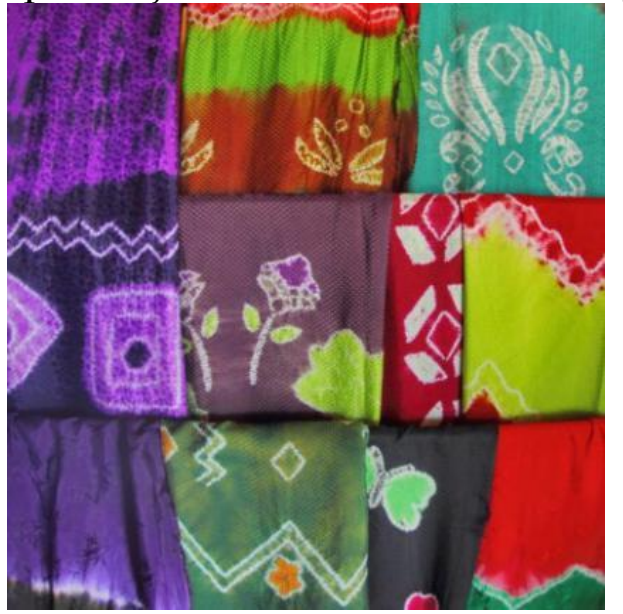

Gambar 24. Kain Sasirangan yang menggunakan zat pewarna sintetis (Sumber: https://www.kompasiana.com)

Serangkaian makna simbolis dari ragam warna kain Sasirangan yang sebelumnya diperoleh dari pewarna alami kini telah mengalami pergeseran. Ragam warna kain Sasirangan kini hanya sebatas strategi penjualan yang disesuaikan dengan selera pasar. Kisah mengenai kemampuan magis kain Sasirangan sebagai obat bagi berbagai penyakit pun kini hanya menjadi bumbu bagi marketing kain tersebut.

Keefektifan dan efisiensi waktu serta biaya produksi dalam penggunaan zat pewarna sintetis untuk kain Sasirangan memiliki dampak negatif. Bahan-bahan pewarna sintetis seperti naphtol, indigosol, reaktif dan indanthreen menghasilkan limbah cair berwarna pekat dalam jumlah yang cukup besar (Hardini dalam Nintasari 2016:26). Limbah cair yang 
dihasilkan ini mengandung berbagai macam zat pencemar, seperti fenol; senyawaan organik sintesis; dan logam berat (Irawati dalam Nintasari 2016:26).

\begin{tabular}{|c|c|c|c|}
\hline No. & Kain Sasirangan & $\begin{array}{l}\text { Fungsi dan Makna } \\
\text { Simbolis }\end{array}$ & $\begin{array}{l}\text { Pergeseran yang terjadi } \\
\text { saat ini }\end{array}$ \\
\hline 1. & $\begin{array}{l}\text { Sarung (tapih } \\
\text { bahalai) }\end{array}$ & $\begin{array}{l}\text { Dikenakan sebagai } \\
\text { selimut untuk } \\
\text { mengobati penyakit } \\
\text { demam atau gatal-gatal }\end{array}$ & $\begin{array}{l}\text { Saat ini sudah tidak lagi } \\
\text { digunakan untuk } \\
\text { pengobatan }\end{array}$ \\
\hline 2. & $\begin{array}{l}\text { Bebat (babat atau } \\
\text { stagen) }\end{array}$ & $\begin{array}{l}\text { Dililit di perut } \\
\text { dimaksudkan sebagai } \\
\text { sarana untuk } \\
\text { menyembuhkan } \\
\text { penyakit diare, disentri, } \\
\text { kolera, dan sejenis } \\
\text { penyakit perut lainnya. }\end{array}$ & $\begin{array}{l}\text { Saat ini sudah tidak lagi } \\
\text { digunakan untuk } \\
\text { pengobatan }\end{array}$ \\
\hline 3. & $\begin{array}{l}\text { Selendang } \\
\text { (kakamban) }\end{array}$ & $\begin{array}{l}\text { Dililit di kepala atau } \\
\text { disampirkan sebagai } \\
\text { penutup kepala } \\
\text { dimaksudkan sebagai } \\
\text { sarana untuk } \\
\text { menyembuhkan sakit } \\
\text { kepala sebelah } \\
\text { (migraine) }\end{array}$ & $\begin{array}{l}\text { Saat ini sudah tidak lagi } \\
\text { digunakan untuk } \\
\text { pengobatan }\end{array}$ \\
\hline 4. & Ikat kepala (laung) & $\begin{array}{l}\text { Dililit di kepala } \\
\text { dimaksudkan sebagai } \\
\text { sarana untuk } \\
\text { menyembuhkan } \\
\text { penyakit kepala seperti } \\
\text { pusing atau kepala } \\
\text { berdenyut-denyut }\end{array}$ & $\begin{array}{l}\text { Saat ini sudah tidak lagi } \\
\text { digunakan untuk } \\
\text { pengobatan }\end{array}$ \\
\hline 5. & $\begin{array}{l}\text { Motif modang } \\
\text { (ketupat merah) }\end{array}$ & $\begin{array}{l}\text { Untuk menyembuhkan } \\
\text { berbagai penyakit }\end{array}$ & $\begin{array}{l}\text { Saat ini sudah jarang } \\
\text { digunakan untuk } \\
\text { pengobatan }\end{array}$ \\
\hline 6. & $\begin{array}{l}\text { Motif kangkung } \\
\text { berombak }\end{array}$ & $\begin{array}{l}\text { Untuk sakit kepala yang } \\
\text { seperti terombang } \\
\text { ambing }\end{array}$ & $\begin{array}{l}\text { Saat ini sudah tidak lagi } \\
\text { digunakan untuk } \\
\text { pengobatan }\end{array}$ \\
\hline
\end{tabular}




\begin{tabular}{|c|c|c|c|}
\hline 7. & $\begin{array}{l}\text { Motif naga balimbur } \\
\text { (naga meliuk) }\end{array}$ & $\begin{array}{l}\text { Untuk sakit yang } \\
\text { melilit-lilit }\end{array}$ & $\begin{array}{l}\text { Saat ini sudah tidak lagi } \\
\text { digunakan untuk } \\
\text { pengobatan }\end{array}$ \\
\hline 8. & $\begin{array}{l}\text { Motif buaya, lipan, } \\
\text { naga atau ular }\end{array}$ & $\begin{array}{l}\text { Untuk mengobati pasien } \\
\text { berdasarkan "roh" yang } \\
\text { mengganggu pasien } \\
\text { tersebut }\end{array}$ & $\begin{array}{l}\text { Saat ini sudah tidak lagi } \\
\text { digunakan untuk } \\
\text { pengobatan }\end{array}$ \\
\hline 9. & Warna kuning (1) & $\begin{array}{l}\text { Dalam kepercayaan } \\
\text { agama Hindu dipakai } \\
\text { oleh Dewa Wisnu, } \\
\text { Krisna dan Ganesha; } \\
\text { menjadi simbol } \\
\text { kekeramatan dan } \\
\text { penangkal dari roh } \\
\text { jahat. }\end{array}$ & $\begin{array}{l}\text { Saat ini sudah tidak lagi } \\
\text { digunakan untuk } \\
\text { pengobatan }\end{array}$ \\
\hline 10. & Warna Kuning (2) & $\begin{array}{l}\text { Pemakainya sedang } \\
\text { dalam proses mengobati } \\
\text { penyakit kuning } \\
\text { (bahasa Banjar kana } \\
\text { wisa) }\end{array}$ & $\begin{array}{l}\text { Saat ini sudah tidak lagi } \\
\text { digunakan untuk } \\
\text { pengobatan }\end{array}$ \\
\hline 11. & Warna Merah & $\begin{array}{l}\text { Pemakainya sedang } \\
\text { dalam proses mengobati } \\
\text { penyakit sakit kepala } \\
\text { dan imsonia }\end{array}$ & $\begin{array}{l}\text { Saat ini sudah tidak lagi } \\
\text { digunakan untuk } \\
\text { pengobatan }\end{array}$ \\
\hline 12. & Warna Hijau & $\begin{array}{l}\text { Pemakainya sedang } \\
\text { dalam proses mengobati } \\
\text { penyakit lumpuh } \\
\text { (stroke) }\end{array}$ & $\begin{array}{l}\text { Saat ini sudah tidak lagi } \\
\text { digunakan untuk } \\
\text { pengobatan }\end{array}$ \\
\hline 13. & Warna Hitam & $\begin{array}{l}\text { Pemakainya sedang } \\
\text { dalam proses mengobati } \\
\text { penyakit demam dan } \\
\text { kulit gatal-gatal }\end{array}$ & $\begin{array}{l}\text { Saat ini sudah tidak lagi } \\
\text { digunakan untuk } \\
\text { pengobatan }\end{array}$ \\
\hline 14. & Warna Ungu & $\begin{array}{l}\text { Pemakainya sedang } \\
\text { dalam proses mengobati } \\
\text { penyakit sakit perut } \\
\text { (diare, disentri, dan } \\
\text { kolera) }\end{array}$ & $\begin{array}{l}\text { Saat ini sudah tidak lagi } \\
\text { digunakan untuk } \\
\text { pengobatan }\end{array}$ \\
\hline
\end{tabular}




\begin{tabular}{|l|l|l|l|}
\hline 15. & Warna Cokelat & $\begin{array}{l}\text { Pemakainya sedang } \\
\text { dalam proses mengobati } \\
\text { penyakit tekanan jiwa }\end{array}$ & $\begin{array}{l}\text { Saat ini sudah tidak lagi } \\
\text { digunakan untuk } \\
\text { pengobatan }\end{array}$ \\
\hline
\end{tabular}

Tabel 1. Analisa pergeseran fungsi dan makna simbolis kain Sasirangan

Dalam beberapa tahun ini, kesadaran masyarakat akan bahaya limbah zat pewarna sintetis bagi lingkungan memunculkan trend penggunaan kembali zat pewarna alami untuk beragam produk tekstil, termasuk kain Sasirangan. Pada Mei 2017, Pemrov Kalsel membuat pelatihan pewarnaan kain Sasirangan menggunakan zat pewarna alami bagi para pengrajin. Pada pelatihan tersebut dijelaskan bahwa ada banyak bahan alami yang bisa dijadikan bahan pewarna antara lain, daun rambutan, kulit batang pohon mahoni, akar mengkudu, bubuk gergajian kayu ulin, daun ketapang, daun mangga, daun dan putri malu, hingga daun jambu.

Selain kesadaran akan kelestarian lingkungan, ternyata pangsa pasar akan produk berbahan alami juga cukup menjanjikan. Ragam warna yang dihasilkan oleh zat pewarna alam yang cenderung lebih soft disukai oleh banyak orang dari luar daerah dan dari luar negeri. Proses untuk membuat Sasirangan berbahan alami ini memang cukup rumit, terutama untuk menghasilkan ekstrak daun hingga menghasilkan warna yang diinginkan rata-rata butuh waktu sampai empat jam. Rumitnya proses pembuatan kain Sasirangan berbahan alami ini mengakibatkan harganya relatif lebih mahal dibandingkan dengan yang menggunakan zat pewarna sintetis (http://banjarmasin.tribunnews.com)

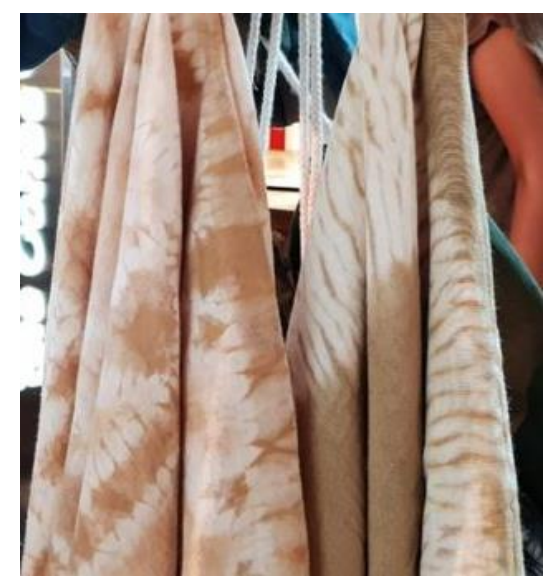

Gambar 25. Kain Sasirangan dengan pewarna alami (Sumber: https:// lifestyle. kompas.com)

Menurut Setiawan dalam Nintasari (2016:2) zat pewarna alami menghasilkan ragam warna yang indah dan khas, yang sulit ditiru oleh zat pewarna sintetis. Sebagian besar zat pewarna alami diambil dari tumbuh-tumbuhan yang merupakan pewarna yang mudah terdegradasi. Bagian- bagian tanaman yang dapat dipergunakan untuk pewarna alami adalah kulit, ranting, batang, daun, akar, biji, bunga, dan getah. Setiap tanaman dapat merupakan sumber zat pewarna alami karena mengandung pigmen alam. Potensi sumber zat pewarna alami ditentukan oleh intensitas warna yang dihasilkan 
serta bergantung pada jenis zat warna yang ada dalam tanaman tersebut.

Ketersediaan beberapa bahan pewarna alam saat ini sudah terbatas. Kayu ulin atau kayu besi merupakan salah satu pewarna alam yang kini jumlahnya sudah langka. Kayu ulin pernah menjadi komoditas pokok di Banjarmasin yang terkenal karena kekuatannya. Eksploitasi hutan di Kalimantan dimana lahan-lahan hijau tempat kayu ulin tumbuh habis diganti dengan perkebunan sawit, hal ini mengakibatkan ketersediaan kayu ulin menjadi langka. Kayu ulin yang kini dipergunakan untuk zat pewarna kain Sasirangan merupakan hasil limbah pengrajin pengolahan kayu di sekitar lokasi pengrajin.

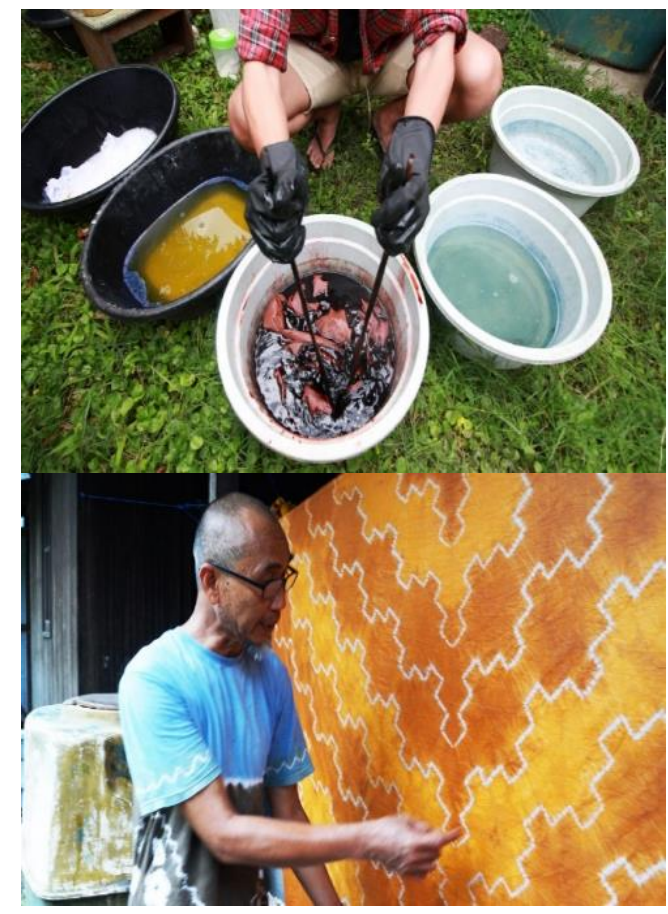

Gambar 26. Atas: Proses pencelupan kain menggunakan kayu ulin. Bawah: Pengrajin dan kain Sasirangan yang menggunakan pewarna alami (Sumber: https://medium .com)

Kembalinya sejumlah pengrajin menggunakan zat pewarna alami tidak turut mengembalikan makna simbolis dari warna yang terkandung dalam kain Sasirangan. Ragam warna kain Sasirangan kini hanya menjadi salah satu unsur desain yang merupakan nilai jual dari komoditas lokal khas Kalimantan Selatan ini. Selain sebagai unsur desain, ragam warna kain Sasirangan kini menegaskan pangsa pasarnya masing-masing. Ragam warna yang dihasilkan oleh zat pewarna sintetis dan ragam warna yang dihasilkan oleh zat pewarna alami memiliki segmen pasar yang berbeda.

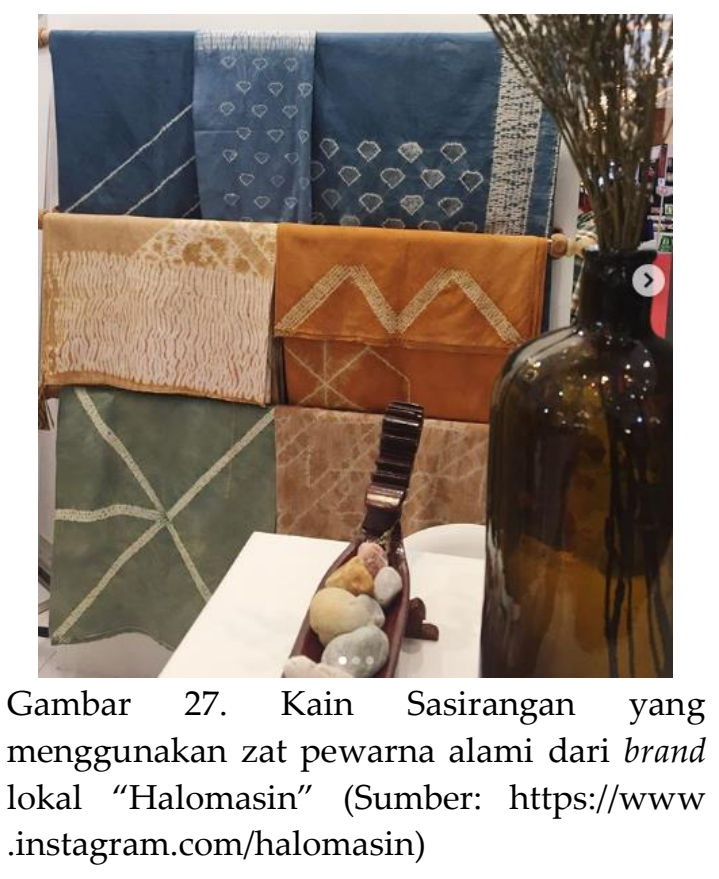

Ragam produk kain Sasirangan yang menggunakan zat pewarna alami cenderung disukai oleh pasar dari luar daerah Kalimantan Selatan dan dari luar negeri. Kini, terdapat brand lokal yang menawarkan produk kain Sasirangan berbahan alami dengan desain produk yang eksklusif. 


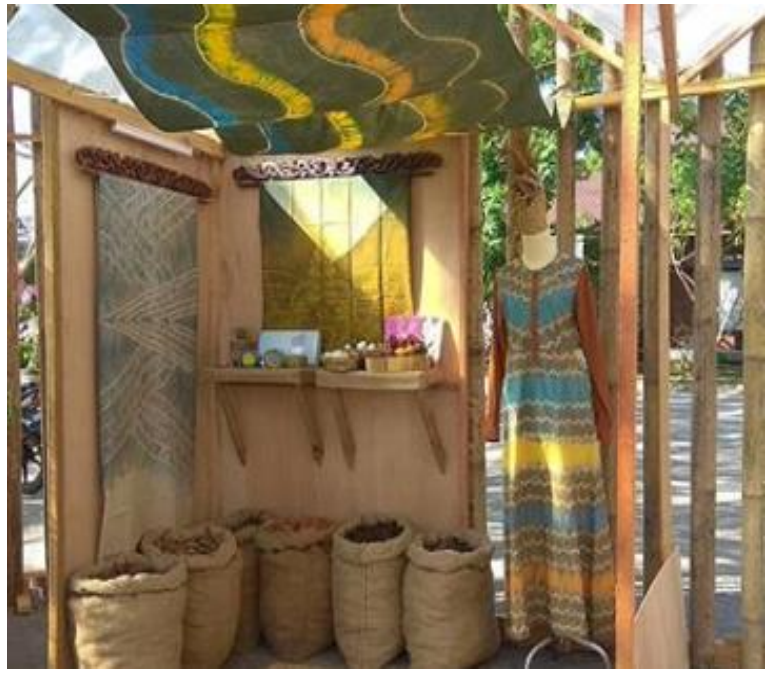

Gambar 28. "Assalam," Aku Suka Sasirangan Warna Alam, brand lokal yang memproduksi kain Sasirangan dengan pewarna alami (Sumber: https://www.instagram.com /sasir anganwarnaalam/?hl=en)

\section{SIMPULAN}

Berdasarkan hasil analisa dari studi literatur dan data yang diperoleh, pergeseran fungsi dan makna simbolis yang terjadi pada kain Sasirangan adalah sebagai berikut:

1. Pergeseran fungsi dari kain untuk keperluan pengobatan berbagai penyakit menjadi kain komoditas lokal Kalimantan Selatan yang digunakan untuk menjadi bahan baku beragam produk seperti tas, baju, sandal dan dompet

2. Pergeseran makna simbolis kain Sasirangan dari segi motif adalah: awalnya motif kain Sasirangan mengandung berbagai arti dan merupakan metafora dari penyakit yang hendak diobati, kini motif kain Sasirangan dimodifikasi menjadi motif baru yang terkesan lebih modern. Bahkan bermunculan motif-motif baru yang sama sekali berbeda dengan motif klasiknya

3. Pergeseran makna simbolis kain Sasirangan dari segi warna adalah: pada awalnya warna kain Sasirangan ditentukan berdasarkan penyakit yang diderita oleh seseorang, kini ragam warnanya hanya sebatas unsur desain yang menjadi salah satu nilai jual utama dari kain Sasirangan.

4. Ragam warna kain Sasirangan kini berperan sebagai penentu segmen pasar. Ragam warna yang dihasilkan oleh zat pewarna sintetis dan ragam warna yang dihasilkan oleh zat pewarna alam memiliki segmen pasarnya masingmasing.

\section{REFERENSI}

GANIE, T. N. 2014. Sasirangan Kain Khas Tanah Banjar. Kalimantan Selatan: Tuas Media

HARDINI, RISNAWATI, FAUZI, dan KOMARI. 2009. Pemanfaatan Rumput Alang-Alang (Imperata cylindrica) sebagai Biosorben $\mathrm{Cr}$ (VI) pada Limbah Industri Sasirangan dengan Metode Teh Celup. Sains dan Terapan Kimia. 5(1):34-44. 
IRAWATI dan UMI. 2011. Pengolahan

Limbah Cair Sasirangan

Menggunakan Filter Arang Aktif

Cangkang Kelapa Sawit

Berlapiskan Kitosan setelah

Koagulasi dengan FeSO4. Sains

dan Terapan Kimia. 2(1) : 57-73

KHOLIS, N. 2016. Kain Tradisional

Sasirangan "Irma Sasirangan"

Kampung Melayu Kalimantan

Selatan. Skripsi Program Studi

Pendidikan Seni Rupa Fakultas

Bahasa dan Seni Universitas

Yogyakarta.

NINTASARI dan AMALIYAH. 2016.

Ekstraksi Zat Warna Alam dari

Kayu Ulin (Eusideroxylon

Zwageri), Kayu Secang

(Caesalpinia sp) dan Kayu

Mengkudu (Morinda Citrifolia)

untuk Bahan Warna Kain

Sasirangan. Jurnal Riset Industri

Badan Penelitian dan

Pengembangan Industri

ROSYADI, M. D. 2017. Pengenalan

Motif Dasar pada Kain

Sasirangan Menggunakan Metode

Template

Matching.

Banjarmasin:

Jurnal
Technologia Fakultas Teknik

Universitas Islam Kalimantan

Muhammad Arsyad Al-

Banjary

SEMAN, S. 2007. Sasirangan Kain Khas

Banjar. Kalimantan Selatan:

Lembaga Pengkajian dan

Pelestarian Budaya Banjar

SETIAWAN, A.P. 2003. Potensi

Tumbuh-Tumbuhan bagi

Penciptaan Ragam Material

Finishing untuk Interior. Dimensi

Interior 1: 46-60.

WIJAYA, FIANTO, dan HIDAYAT.

2015. Penciptaan Buku Ilustrasi

Kain Sasirangan Sebagai Upaya

Promosi Seni Budaya Banjarmasin

kepada Remaja. Surabaya: Jurnal

DKV STIKOM

https://www.indonesiakaya.com/

jelajah-indonesia /detail/kain-

Sasirangan diakses pada 28

Agustus 2018 pk.15:28 WIB

https://asikbelajar.com/Sasirangan-

sejarah-arti-dan-motif/ diakses

pada 15 Agustus 2018 pk.14:28

https://medium.com/@san

tikasyaravina/Sasirangan-

kisah-karsawanita-banjar- 
menuju-kesejahteraan diakses

pada 15 Agustus 2018 pk.15:55 wib

https://warisanbudaya. kem

dikbud.go.id/?newdetail\&deta

ilCatat=937 diakses pada 29

Agustus 2018 pk.09:44 WIB

http://banjarmasin.tribunnews.com/2

017/05/16/newsvideo-perajin-

sasirang an-belajar-teknik-

pewarna-bahan alami diakses

pada 29 Agustus 2018 pk.

15:12 WIB

https://lifestyle.kompas.com/read/201

8/05/27/143126920/agar-tak-

luntur-simak-tips-merawat-

kain-dengan-pewarna-alam

diakses pada 29 Agustus 2018

pk.15:19 WIB

https://www.kompasiana.com/dhave

/593610db4d64f6304c0d6392/b

atik-sasirangan-makna-di-

balik-sentuhan-tangan diakses

pada 29 Agustus 2018 pk.

16:12 WIB

http://blogmayatkj2dinamis.com/

diakses pada 29 Agustus 2018

pk.15:49 WIB http://banjarmasin.tribunnews.com/2 017/09/23/ami-sasirangankreatif-bikin-motif-modern diakses oleh 30 Agustus 2018 pk.13.52 WIB

http://banjarmasin.tribunnews.com/2 017/12/09/motif-lidi-moderenjadi-andalan-zahra-sasiranganbegini-bentuknya?page $=2$ diakses pada 30 Agustus 2018 pk.13:53 WIB

https://sasiranganwarnaalam.blogspo t.com/2013/07/sasiranganwarna-alam-khasbanjarmasin_6831.html diakses pada 30 Agustus 2018 pk.14:37 WIB 